\title{
Prediction of postoperative pain and duration of hospitalization using two anxiety measures
}

\author{
Saskia Boeke ${ }^{1}$, Hugo J. Duivenvoorden ${ }^{1}$, Frans Verhage ${ }^{1}$ and Albert Zwaveling ${ }^{2}$ \\ ' Department of Medical Psychology and Psychotherapy, Erasmus University Rotterdam, Rotterdam (The Netherlands), \\ and ${ }^{2}$ Department of Surgery, University Hospital Leiden, Leiden (The Netherlands)
}

(Received 26 September 1989, revision received 12 November 1990, accepted 20 November 1990)

\begin{abstract}
Summary This study examined the extent to which measures of anxiety could predict pain and the length of hospitalization following surgery in 111 patients with gallstones over and above what could be predicted on the basis of biographical and medical status variables. Self-reported pain on the third day postoperative could hardly be explained by the variables measured. Preoperative anxiety did not increase the value of the prediction.

Age, type of surgery, cystitis and wound infection explained a significant proportion of the variance in postoperative hospital stay. Over and above these variables, A-state on the third postoperative day and also A-state and specific anxiety measured 1 day before surgery exerted a significant increase on the values of prediction of the length of postoperative hospitalization.
\end{abstract}

Key words: Prediction; Anxiety; Postoperative recovery; Pain

\section{Introduction}

Hospital patients admitted for an operation often find themselves in a threatening situation. Anticipation of harm during surgery and the anticipation of pain and disability postoperatively give rise to many inconsistent feelings, fear being the prevalent one. It has been well documented that psychological stress can induce numerous physical effects, ranging from increased sympathetic-adrenomedullary activity [6] to increased susceptibility to disease [8]. It is, therefore, possible that psychological stress has a negative effect on physical recovery following surgery. Many studies have been carried out to explore the relationship between preoperative psychological factors and postoperative recovery $[1,4,5,9-13,15-17,19-23]$. Their findings are inconsistent and, with the exception of Taenzer et al. [20], the effects of medical history and physical trauma were not analysed. George et al. [7] stated that 'the physical trauma caused by the surgery could have direct effects

Correspondence to: Saskia Boeke, Ph.D., Department of Medical Psychology and Psychotherapy, Erasmus University Rotterdam, P.O. Box 1738, 3000 DR Rotterdam, The Netherlands. upon recovery and indirect effects on the psychological variables under investigation.'

The present report derives from a larger study which examined the effect of intra-operative auditory registration on postoperative course. The negative results of that study have been reported elsewhere [3]. Therefore, the nature of the present study must be considered to be exploratory. The aim was to determine biographical, medical status and psychological factors having differential contribution in the explanation of pain and duration of hospital stay after surgery. Multiple regression analyses were selected particularly to determine whether the contribution of anxiety measured preoperatively would add to the explained variation in pain and duration of hospital stay after surgery over and above that which is explained by biographical, medical status and postoperative anxiety variables.

\section{Method}

\section{Subjects}

Over a 3 year period, Dutch-speaking patients, awaiting elective cholecystectomy at a university training hospital (head: A.Z.) were studied. Patients with a hear- 
ing impairment and associated preoperative disease and those from psychiatric hospitals were excluded. Nine patients refused and 111 patients ( $37 \mathrm{men}$ and 74 women), aged 19-86 years (mean: 53.6. S.D.: 14.8) gave informed consent. The investigation was approved by the hospital's committee of medical ethics.

\section{Materials}

From the Dutch version of the State-Trait Anxiety Inventory (STAI) [14,18], the State Anxiety (A-state) scale was used to measure transient anxiety states. In contrast to this measure of general state anxiety, items were scored measuring the degree of worry about the surgery and about the anaesthesia on two 5-point rating scales $[10,22]$. A measure was created by combining these 2 anxiety ratings to form a single index of the patient's specific anxiety for the operation, whatever the source, as follows: if at least 1 of the 2 ratings is 4 and/or 5, the composite score must be coded 'high' (3); if both ratings are 1 and/or 2, the composite score must be coded 'low' (1); in the remaining cases, the composite score must be given an intermediary code 'medium' (2).

A 5-point rating scale was administered for pain: did you have any pain yesterday?, with the extremes 'no, none or hardly any' (1) and 'yes, a great deal' (5).

The following variables were obtained from the patients' hospital charts: number of previous operations, duration of preoperative hospital stay, duration of anaesthesia (from initial incision until the beginning of closure of the peritoneum), the presence of wound infection and cystitis. The postoperative hospital stay was assessed by asking the surgeon on which day the patient was ready or should have been ready to go home.

\section{Procedure}

One day before surgery (T1), the patients completed the A-state and the 2 rating scales for specific anxiety. On the third day (day of surgery $=0 ; T 2$ ), the A-state was completed for the second time. On the same day, the rating scale for pain was administered.

\section{Methods of analysis}

Pearson product-moment correlations were calculated for the biographical, medical status and anxiety variables on the one hand and the outcome measures on the other.

The method of hierarchical multiple linear regression analysis was applied in order to estimate the 2 outcome measures (postoperative pain and hospital stay).

The independent variables were entered in 5 sets: (1) biographical variables (age and sex); (2) peri-operative medical status variables (preoperative hospital stay, previous operations, kind of surgery and duration of anacsthesia); (3) postoperative medical status variables (wound infection and cystitis); (4) postoperative anxiety
TABLE I

MEANS AND PERCENTAGES OF THE INDEPENDENT VARIABLES AND OUTCOME MEASURES $(n=111)$

\begin{tabular}{|c|c|c|c|}
\hline & Mean & S.D. & 晃 \\
\hline \multicolumn{4}{|l|}{ Biographical variables } \\
\hline Age (years) & 53.6 & 14.8 & \\
\hline \multicolumn{4}{|l|}{ Sex: } \\
\hline Male & & & 33 \\
\hline Female & & & 67 \\
\hline \multicolumn{4}{|l|}{ Medical status variables } \\
\hline Preoperative stay (days) ${ }^{1}$ & 1.4 & 0.7 & \\
\hline Previous operations & 1.9 & 1.8 & \\
\hline Cholecystectomy & & & 89 \\
\hline $\begin{array}{l}\text { Cholecystectomy and } \\
\text { choledochotomy }\end{array}$ & & & 11 \\
\hline Duration of anaesthesia (min) & 121.4 & 41.0 & \\
\hline Wound infection & & & 14 \\
\hline Cystitis & & & 15 \\
\hline \multicolumn{4}{|l|}{ Anxiety variables } \\
\hline \multicolumn{4}{|l|}{ Preoperative specific anxiety: } \\
\hline Low & & & 33 \\
\hline Medium & & & 31 \\
\hline High & & & 36 \\
\hline Preoperative A-state & 41.2 & 11.2 & \\
\hline Postoperative A-state & 36.4 & 11.0 & \\
\hline \multicolumn{4}{|l|}{ Outcome measures } \\
\hline Pain on third day & 2.8 & 1.2 & \\
\hline Postoperative stay (days) 2.3 & 11.1 & 3.6 & \\
\hline
\end{tabular}

For administrative reasons, $21(19 \%)$ patients spent extra time in hospital before surgery. ${ }^{2}$ Discharge time was the moment when the surgeon declared the patient was ready for discharge. ${ }^{3} n=110$.

measure (A-state at T2); and (5) preoperative anxiety measures (specific anxiety and A-state at T1). The levels of criteria for entry and for removal were fixed at $P<0.05$ and $P>0.10$, respectively. Finally, by adding the anxiety variables measured preoperatively, it was possible to determine whether these variables had substantial incremental value on predicting the outcome measures (self-reported pain and hospital stay) of patients following cholecystectomy. A separate regression analysis was conducted for each outcome measure.

\section{Results}

\section{Descriptive and correlational analyses}

Twelve cholecystectomy patients also underwent a choledochotomy. The postoperative hospital stay of 1 patient was considered 'missing' because of complications resulting from another illness.

Table I displays the data on biographical, medical status and anxiety variables and outcome measures.

With regard to the relationships between the independent variables, sex correlated significantly with the subject's preoperative A-state and specific anxiety $(r=$ $0.35, P<0.0001$ and $r=0.34, P<0.0001$, respectively). 
TABLE II

SIGNIFICANT CORRELATIONS BETWEEN THE INDEPENDENT VARIABLES AND OUTCOME MEASURES

\begin{tabular}{|c|c|c|}
\hline & $\begin{array}{l}\text { Pain on the } \\
\text { third day } \\
(\mathrm{n}=111)\end{array}$ & $\begin{array}{l}\text { Postoperative } \\
\text { hospital stay } \\
(n=110)\end{array}$ \\
\hline \multicolumn{3}{|c|}{ Biographical variables } \\
\hline \multicolumn{3}{|l|}{ Sex } \\
\hline Age & & $0.28 * *$ \\
\hline \multicolumn{3}{|c|}{ Medical status variables } \\
\hline \multicolumn{3}{|c|}{ Preoperative stay } \\
\hline \multicolumn{3}{|c|}{ Previous operations } \\
\hline Type of surgery & & $0.20 *$ \\
\hline \multicolumn{3}{|c|}{ Duration of anaesthesia } \\
\hline \multicolumn{2}{|l|}{ Cystitis } & $0.45 * * * *$ \\
\hline \multicolumn{3}{|l|}{ Anxiety variables } \\
\hline \multicolumn{3}{|c|}{ Specific anxiety (T1) } \\
\hline A-state (T1) & $0.20^{*}$ & \\
\hline A-state (T2) & $0.30 * * *$ & $0.39 * * * *$ \\
\hline
\end{tabular}

Furthermore, preoperative A-state correlated significantly with specific anxiety preoperatively and A-state on the third day $(r=0.56, P<0.0001$ and $r=0.30$, $P<0.001$, respectively). Table II presents the statistically significant correlations between the biographical, medical status and anxiety variables on the one hand and outcome measures on the other.

Among the highly significant correlations $(P<0.01)$, there was a positive relationship between self-reported pain on the third day and A-state on the third day. Postoperative hospital stay was positively correlated with age, wound infection and with A-state on the third day.

\section{Predictability of postoperative pain}

Table III displays the results of the hierarchical regression analysis for pain on the third day. A small, but significant, proportion of variance in pain on the third day could be explained on the basis of a combination of the independent variables $\left(R^{2}=12 \% ; R^{2}\right.$ adjusted $=10 \%$ ). None of the biographical variables explained a significant proportion of the variance in pain

\section{TABLE III}

SUMMARY OF HIERARCHICAL REGRESSION ANALYSIS FOR POSTOPERATIVE PAIN $(\mathrm{n}=111)$

\begin{tabular}{|c|c|c|c|c|}
\hline $\begin{array}{l}\text { Independent } \\
\text { variables }\end{array}$ & $M R^{2}$ & $\begin{array}{l}R^{2} \\
\text { change }\end{array}$ & $\begin{array}{l}F \text { ratio for } \\
R^{2} \text { change }\end{array}$ & Beta \\
\hline Cystitis & 0.02 & 0.02 & 42.46 & -0.16 \\
\hline A-state (T2) & 0.12 & 0.10 & $12.03 * * *$ & $0.31 * * *$ \\
\hline
\end{tabular}

*** $P<0.001$.
TABLE IV

SUMMARY OF HIERARCHICAL REGRESSION ANALYSIS FOR DURATION OF POSTOPERATIVE HOSPITAL STAY $(\mathrm{n}=$ $110)$

\begin{tabular}{lclcc}
\hline $\begin{array}{l}\text { Independent } \\
\text { variables }\end{array}$ & $M R^{2}$ & $\begin{array}{l}R^{2} \\
\text { change }\end{array}$ & $\begin{array}{l}F \text { ratio for } \\
R^{2} \text { change }\end{array}$ & Beta \\
\hline $\begin{array}{l}\text { Age } \\
\text { Preoperative }\end{array}$ & 0.08 & 0.08 & $9.15^{* *}$ & $0.19^{*}$ \\
$\quad$ & & & & -0.12 \\
$\quad$ hospital stay & & & & $0.17^{*}$ \\
$\begin{array}{l}\text { Type of surgery } \\
\text { Cystitis }\end{array}$ & 0.12 & 0.04 & 2.65 & $0.15^{* * *}$ \\
$\begin{array}{l}\text { Wound infection } \\
\text { A-State (T2) }\end{array}$ & 0.32 & 0.20 & $15.40 * * * *$ & $0.40^{* * * *}$ \\
Specific anxiety (T1) & 0.39 & 0.07 & $12.22 * * *$ & $0.33^{* * * *}$ \\
A-State (T1) & 0.45 & 0.06 & $5.48^{* *}$ & $-0.26^{* *}$ \\
\hline$* P<0.05 ; * * P<0.01 ; * * * P<0.001 ; * * * * P<0.0001$.
\end{tabular}

on the third day. Of the medical status variables, cystitis had an incremental value ( $2 \%$ of variance explained).

With respect to the anxiety variables, only postoperative A-state accounted significantly for an additional $10 \%$ of the variance in this outcome variable. Patients with higher A-state on the third day reported more pain on that day over and above the contribution of the medical stalus variable cystitis.

\section{Predictability of postoperative hospital stay}

Table IV summarizes the results of the hierarchical regression analysis for duration of postoperative hospital stay. On the basis of a combination of the independent variables, $45 \%$ of the variance in postoperative hospital stay ( $R^{2}$ adjusted $=41 \%$ ) could be explained.

With respect to the biographical variables, age explained a significant amount of the variance. Postoperatively, older patients stayed longer in hospital than younger patients. The peri-operative medical status variables (the type of surgery and duration of preoperative hospital stay) and, in addition to these, the postoperative medical status variables (cystitis and wound infection) emerged as important predictors. Cholecystectomy patients who stayed longer in hospital preoperatively and those who also underwent choledochotomy had a longer stay in hospital after surgery. The duration of postoperative hospital stay was longer for patients with wound infection. In addition to biographical and medical status variables, A-state on the third day contributed significantly to the variance. Patients with higher A-state on the third day stayed longer in hospital postoperatively. Over and above the effect of all these variables, specific anxiety and A-state measured preoperatively turned out to be of predictive value. Patients with higher specific anxiety and lower A-state measured 1-day before surgery had a longer postoperative hopital stay. 


\section{Discussion}

The present study executed in a university training hospital has some shortcomings since it derives from a larger study and thus must be regarded as being exploratory in nature. To protect patients from the burden of investigations, that have no direct hearing on their medical treatment, only 1 limited measure of pain and 2 state measures of anxiety were administrated.

The present study examined biographical, medical status, anxiety variables and recovery measures in cholecystectomy patients. The main finding of our study was that there were relationships between anxiety measures and postoperative pain and duration of hospital stay. The regression analyses clearly demonstrated that the correlations between anxiety measures and recovery indices, after controlling for biographical and medical status variables, were not the same as the bivariate correlations. This finding suggests that many previous research results have been confounded by medical status variables $[1,4,5,9-13,15-17,19,21-23]$. It also clearly adds to the evidence that anxiety may be related to the recovery process.

As the proportion of explained variance in pain reported on the third day was less than $15 \%$, this is felt to be too low for clinical predictions. Preoperative Astate had a significant correlation with pain, but made no incremental contribution to the prediction of the variance in pain beyond the role of biographical, medical status variables and postoperative anxiety. It is possible that the pain variance in this study was not sufficiently sensitive to be affected by preoperative anxiety variables. The variable consisted of only one 5 -point rating scale for pain intensity.

In a different study [16], pain intensity postoperatively could be predicted for $22 \%$ on the basis of information patients had received regarding their surgery and on their preoperative A-state score. Furthermore, in a recent study [20], several medical status and psychological variables accounted for about $46 \%$ of the variance in the average pain score. Trait anxiety and neuroticism, measured approximately 2 weeks prior to surgery, were the most important predictors.

In all likelihood, trait measures assessed some weeks prior to the patient's surgery, give a better prediction of postoperative pain measures than trait and/or state measures assessed 1 day before surgery.

In contrast to the small amount of variance in pain intensity explained by the independent variables in the present study, $45 \%$ of the variance in duration of postoperative hospital stay could be accounted for by the independent variables. Postoperative hospital stay was explained by a combination of biographical, medical status and anxiety variables. Older patients and patients, who also underwent choledochotomy had a longer stay in hospital after surgery. The duration of postoper- ative hospital stay was longer for patients with wound infection. This outcome was not unexpected, but it clearly illustrates the importance of taking medical status variables into account in studies on the effect of psychological factors on postsurgical recovery. The medical status variables may be of even greater significance in more invasive surgical procedures. Further studies are needed to determine whether the results we obtained for cholecystectomy can be generalized to more major surgery.

Even beyond the effects of age and the 2 medical status variables, anxiety was a significant predictor of this outcome measure. Patients with high A-state 3 days postoperative and particularly patients with high specific anxiety and low A-state measured 1 day before the operation, stayed in hospital longer following the operation. An explanation for the discrepancy between the preoperative levels of specific anxiety and state anxiety as predictors may be that preoperatively, the patients who would be discharged late find it easier to admit worry about the operation because that is more socially acceptable than to report anxiety.

It can be assumed that the 'at risk' patients never got around to preparing themselves for the experiences in the period immediately after the operation ("work of worrying' [9]). As a result, the surgery was a more anxious ('negative') experience, which could be one of the factors which caused these patients to stay in hospital longer. For example: they may have been so overwhelmed by unexpected, but 'normal' pain, discomfort and deprivation after surgery, that this diminished their feelings of well-being and led to a delay in their healing process [2].

The results of this study indicate the need for further research in which trait measures are administered several weeks prior to admission to hospital for surgery and how state variables can be used for peri-operative measurements. A clearer understanding of the relationship between psychological variables and postoperative recovery measures might lead to a prognosticum with regard to the extent to which psychological interventions pre- and postsurgically can improve the recovery process.

\section{Acknowledgements}

This research was supported by Grant 28.730 from the Praeventiefonds.

We thank Marko Jelicic for comments on the manuscript.

\section{References}

1 Auerbach, S.M., Trait-state anxiety and adjustment to surgery, J, Consult. Clin. Psychol., 40 (1973) 264-271.

2 Boeke, S., Duivenvoorden, H., Verhage, F. and Zwaveling, A. 
Relatie tussen peri-operative angst en post-operatief herstel, Ned. Tijdschr. Geneesk., 134 (1990) 483-486.

3 Boeke, S., Bonke, B., Bouwhuis-Hoogerwerf, M.L., Bovill, J.G. and Zwaveling, A., Effects of sound presented during general anaesthesia on postoperative course, Br. J. Anaesth., 60 (1988) $697-702$.

4 Chapman, C.R. and Cox, G.B., Determinants of anxiety in dental surgery patients. In: C.D. Spielberger and I.G. Sarason (Eds.), Stress and Anxiety, Vol. 4, Wiley, New York, 1977, pp. 269-290.

5 Cohen, F. and Lazarus, R.S., Active coping processes, coping dispositions, and recovery from surgery, Psychosom. Med., 35 (1973) 375-389.

6 Cox, T., Stress, University Park Press, Baltimore, MD, 1987, pp. 53-73.

7 George, J.M., Scott, D.S., Turner, S.P. and Gregg, J.M., The effects of psychological factors and physical trauma on recovery from oral surgery, J. Behav. Med., 3 (1980) 291-310.

8 Holmes, T.H. and Masuda, M., Life change and illness susceptibility. In: B.S. Dohrenwend and B.P. Dohrenwend (Eds.), Stressful Life Events: their Nature and Effects, Wiley, New York, 1974, pp. 45-72.

9 Janis, I.L., Psychological Stress, Wiley, New York, 1958.

10 Johnson, J.E., Leventhal, H. and Dabbs, J.M., Contributions of emotional and instrumental response processes in adaptation to surgery, J. Pers. Soc. Psychol., 20 (1971) 55-64.

11 Johnston, M., Preoperative emotional states and postoperative recovery, Adv. Psychosom. Med., 15 (1986) 1-22.

12 Johnston, M. and Carpenter, L., Relationship between pre-operative anxiety and post-operative state, Psychol. Med., 10 (1980) $361-367$.
13 Martinez-Urrutia, A., Anxiety and pain in surgical patients, $\mathbf{J}$. Consult. Clin. Psychol., 43 (1975) 437-442.

14 Ploeg, H.M. Van der, Handleiding voor de Zelf-Beoordelings Vragenlijst, ZBV, STAI-DY, Swets en Zeitlinger, Lisse, 1980.

15 Ray, A. and Fitzgibbon, G., Stress arousal and coping with surgery, Psychol. Med., 11 (1981) 741-746.

16 Scott, L.E., Clum, G.A. and Peoples, J.B., Preoperative predictors of postoperative pain, Pain, 15 (1983) 283-293.

17 Sime, M., Relationship of pre-operative fear, type of coping, and information received about surgery to recovery from surgery, $J$. Pers. Soc. Psychol., 34 (1976) 716-724.

18 Spielberger, C.D., Gorsuch, R.L. and Lushene, R.E., State Trait Anxiety Inventory Manual, Consult. Psychol. Press, Palo Alto, CA, 1970.

19 Spielberger, C.D., Auerbach, S.M., Wadsworth, A.P., Dunn, T.M. and Taulbee, E.S. Emotional reactions to surgery, J. Consult. Clin. Psychol., 40 (1973) 33-38.

20 Taenzer, P., Melzack, R. and Jeans, M.E., Influence of psychological factors on postoperative pain, mood and analgesic requirements, Pain, 24 (1986) 331-342.

21 Wallace, L.M., Pre-operative state anxiety as a mediator of psychological adjustment to and recovery from surgery, Br. J. Med. Psychol., 59 (1986) 253-261.

22 Wilson, J.F., Behavioral preparation for surgery: benefit or harm? J. Behav. Med., 4 (1981) 79-102.

23 Wolfer, J.A. and Davies, C.E., Assessment of surgical patients' preoperative emotional condition and postoperative welfare, Nurs. Res., 19 (1970) 402-414. 